\title{
Perception of a Tracing App During the Covid-19 Pandemic in Germany
}

\author{
Niels HANNEMANN ${ }^{\mathrm{a} 1}$, Nina-Alexandra GÖTZ ${ }^{\mathrm{a}}$, Lisa SCHMIDT ${ }^{\mathrm{a}}$, Ursula HÜBNER ${ }^{\mathrm{b}}$ \\ and Birgit BABITSCH ${ }^{\mathrm{a}}$ \\ ${ }^{a}$ Osnabrück University, Department of New Public Health \\ ${ }^{\mathrm{b}}$ University of Applied Science Osnabrück, Health Informatics Research Group
}

\begin{abstract}
Access to digital technologies depends on the availability of technical infrastructure, but this access is unequally distributed among social groups and newly summarized under the term digital divide. The aim is to analyze the perception of a tracing app to contain Covid-19 in Germany. The results showed that participants with the highest level of formal education rate the app as beneficial and were the most likely to use the app.
\end{abstract}

Keywords. digital divide, education, tracing app, covid-19

\section{Introduction}

Access to digital technologies is socially unequally distributed, which is described by the term "digital divide" and refers to the fact that deprived groups are less involved and benefit less from digital technologies [1-3].

A tracing app was intensively discussed in Germany for the containment of Covid19. The aim of this study is to analyze the perceived usefulness and the intention to use a tracing app to contain Covid-19 stratified by the educational status (ES).

\section{Methods}

Data from an online cross-sectional study were used. 1.570 persons aged between 18-74 years $(\mathrm{MV}=46.08$ years) participated with an equal gender distribution. The ES was measured with the CASMIN classification [4]. Data collection took place between April 29 and May 8, 2020, after relaxations to the shutdown occurred nationwide on April 20.

\section{Results}

Descriptive analysis showed that $31.7 \%$ with a low compared to $39.7 \%$ with a high ES consider the Covid-19 tracing app to be a useful technology and one third of all respondents, were unable to provide a rating of the perceived usefulness of the app.

${ }^{1}$ Corresponding Author, Niels Hannemann, Osnabrück University, Department of New Public Health, School of Human Sciences, Barbarastr. 22c, 49076 Osnabrück, Germany; E-Mail: niels.hannemann@uniosnabrueck.de 
Table 1. Perceived usefulness of the tracing app

\begin{tabular}{llll|l}
\hline $\begin{array}{c}\text { Perceived usefulness of the } \\
\text { tracing app }\end{array}$ & \multicolumn{3}{c}{ Formal level of education } & \multicolumn{1}{c}{$\boldsymbol{\chi}^{2}$} \\
\hline No & low & medium & high & \\
Yes & $29.8 \%$ & $32.0 \%$ & $28.7 \%$ & \\
I can not judge & $31.7 \%$ & $32.9 \%$ & $39.7 \%$ & \\
Not heard about it yet. & $35.0 \%$ & $32.3 \%$ & $30.1 \%$ & \\
\hline Total (n=1.570) & $3.5 \%$ & $2.7 \%$ & $1.4 \%$ & .176 \\
\hline
\end{tabular}

As a tendency, the higher the ES, the more likely the use of the tracing app. Additionally, smartphone ownership is lower among those with low ES.

Table 2. Intention to use the tracing app when it is perceived to be useful

\begin{tabular}{|c|c|c|c|c|}
\hline \multirow[t]{2}{*}{$\begin{array}{l}\text { Intention to use the } \\
\text { tracing app }\end{array}$} & \multicolumn{3}{|c|}{ Formal level of education } & \multirow[t]{2}{*}{$\chi^{2}$} \\
\hline & Low & medium & high & \\
\hline No & $9.1 \%$ & $7.5 \%$ & $9.8 \%$ & \\
\hline Yes & $85.0 \%$ & $89.4 \%$ & $90.2 \%$ & \\
\hline Not a smartphone owner & $5.9 \%$ & $3.0 \%$ & $0.0 \%$ & .095 \\
\hline Total $(\mathrm{n}=1.570)$ & 153 & 265 & 112 & \\
\hline
\end{tabular}

\section{Discussion}

This analysis showed that there were no significant differences between the perceived usefulness of the tracing app and the intention to use the app, according to different levels of ES. This result is contrary to other findings of this study, showing a higher use of digital health technologies that enable patient-to-patient communication and data transmission of health-related information with healthcare providers and health insurers by individuals with higher ES.

\section{Conclusion}

In further research projects, the reasons why the respondents could not assess the usefulness of the tracing app and did not intend to use this app needed to be investigated. Possible explanations could include a lack of technical skills, a general skepticism about digital technologies, or specific caveats regarding to interventions to contain Covid-19.

\section{References}

[1] Cornejo Müller A, Wachtler B, Lampert T. Digital Divide - Soziale Unterschiede in der Nutzung digitaler Gesundheitsangebote. Bundesgesundheitsbl. 2020; 63(2): 185-191.

[2] Robinson L, Cotten SR, Ono H, Quan-Haase A, Mesch G, Chen W, Schulz J, Hale TM, Stern MJ. Digital inequalities and why they matter. Information, Communication \& Society 2015;18(5): 569-582.

[3] Van Dijk J. The deepening divide: inequality in the information society. Thousand Oaks, London, New Delhi: Sage publications; 2005. p 130.

[4] Lechert Y, Schröder JH, Lüttinger P. Die Umsetzung der Bildungsklassifikation CASMIN für die Volkszählung 1970, die Mikrozensus-Zusatzerhebung 1971 und die Mikrozensen 1976-2004. Mannheim; 2006. 